\title{
Novel Variations at Three Different Positions of Prion Protein Coding Gene in Ethiopian Sheep Breeds and the Resistance/Susceptible Status to Classical and Atypical Scrapie
}

\section{Eden Yitna Teferedegn}

Ege University https://orcid.org/0000-0003-2526-1672

Yalcin Yaman

Bandirma Sheep research institute.

Cemal Un ( $\nabla$ cemaluen@gmail.com )

https://orcid.org/0000-0002-4248-9671

\section{Research article}

Keywords: Ethiopian sheep, Novel Variations, Polymorphism, Prion gene, Scrapie Susceptibility

Posted Date: December 19th, 2019

DOl: https://doi.org/10.21203/rs.2.19308/v1

License: (c) (1) This work is licensed under a Creative Commons Attribution 4.0 International License. Read Full License

Version of Record: A version of this preprint was published at BMC Veterinary Research on April 29th, 2020. See the published version at https://doi.org/10.1186/s12917-020-02336-0. 


\section{Abstract}

Background: Classical Scrapie susceptibility in sheep has been linked to three polymorphisms at positions 136, 154, and 171 in the PRNP gene whereas atypical scrapie susceptibility is related to a polymorphism at position 141. Many other variants over the length of the prion protein coding gene were reported. Since infectious prion protein itself seems to be polymorphic, the identified novel PRNP gene variations may play a crucial role in fighting against the emergence of a new form of scrapie disease. Many studies conducted around the world to identify disease resistant status and new variants of $P R N P$ gene in different breeds. However, such in-depth studies have never addressed the African continent's sheep breeds. Therefore, genotyping native Ethiopian sheep breeds PRNP gene provides essential information to the current knowledge. This study aimed to identify potential novel variations in the Ethiopian sheep PRNP gene, thereby determine the uniqueness of the native breeds and predict scrapie status of sheep population based on the genotypes distribution.

Results : Five novel variants were identified in the PRNP gene of native Ethiopian sheep. Four nonsynonymous heterozygous substitutions at H99Q (CAC-->CAA), H99L (CAC->CTA), A116E (GCA-> GAA), A116T (GCA->ACA), and one synonymous N103N (AAC-->AAT) variants were detected. In addition to the novel variations, polymorphisms at $126,127,138,142,146,231$, and 237 positions were also identified. The haplotype ARR was observed only in Menz and Afar breeds with frequencies 0.02 and 0.05 respectively. However, neither ARR/ARR nor VRQ/VRQ genotypes were identified in all of the breeds.

Conclusion: Two of the novel variations at position 99 and 103 that are placed closer to the cleavage site and variant at 116 spotted in the palindrome region along with variants at position 127 in Glycine repeat domain may influence the conformational flexibility of prion protein. The low frequency of ARR haplotype and the sole variant $141 \mathrm{~L}$ demonstrated that Ethiopian sheep are susceptible to classical scrapie and resistant to atypical scrapie. This study provides a valuable dataset that can be potentially integrated into selective breeding strategies against scrapie during inbreeding, crossbreeding and help to take precautious measures.

\section{Background}

Prion diseases are a collective name for infectious neurodegenerative diseases caused by the misfolding of Prion protein [1].The misfolded protein $\left(\mathrm{PrPS}^{\mathrm{Sc}}\right)$ has a different structural dynamic than cellular prion $\left(\mathrm{PrP}^{\mathrm{C}}\right)$. Specific motifs of prion protein were identified in relation to the conversion of $\operatorname{PrP}^{\mathrm{C}}$ to $\operatorname{PrP}^{\mathrm{Sc}}$ [2].

Though the exact underlined disease mechanism is not yet known, transmission and susceptibility of prion diseases have genetic bases. Previous studies identified three polymorphisms (A136V, R154H, and Q171R/H) related to scrapie resistance/susceptibility status in sheep PRNP (prion protein coding gene). ARQ represents susceptible widespread wild type allele; ARR and VRQ are the most resistant and highly susceptible genotypes respectively [7-10]. In atypical scrapie susceptibility is higher in individuals with AHQ, AHQ/ARQ and ARR genotypes along with homozygosity for phenylalanine at position 141 [11]. An 
earlier study linked genotypes such as $A C_{151} R Q$ to prolonged incubation period after scrapie exposure [10]. Together with that, several studies reported polymorphisms such as G126A, G126G, G127G, G127V, G127A, and S138S [3-6] in sheep prion protein with or without direct effect to susceptibility to scrapie.

In the past several years there were efforts to genetically characterize local breeds of many countries in identifying new variants and determining resistance/susceptible haplotypes against scrapie. Based on the findings, measures were taken to control and reduce transmission of transmissible spongiform encephalopathy horizontally and vertically [12-14]. However, there are limited studies that addressed Sub-Saharan African countries such as Ethiopia where livestock is the main economic source and a large proportion of the population depends on livestock products. On the other hand, the ever-increasing animal product demand enhances crossbreeding programs for the last few decades through the importation of exotic animals and the distribution of crossbred F1 in different parts of Ethiopia. Such practices are the potential factors in changing the genetic structure of the population and may introduce new disease susceptible phenotypes $[15,16]$.

Taking in to account the public health, economic and scientific merits genotyping native Ethiopian sheep breeds PRNP gene provides essential information to the current knowledge [17]. This study aimed to identify novel variations in the Ethiopian sheep PRNP gene, thereby determine the uniqueness of the native breeds and predict scrapie status of sheep population based on the genotypes distribution.

\section{Methods}

\section{Animal selection}

Whole blood was taken from genetically unrelated 97 female native sheep breeds (Washera $N=39$, Menz $\mathrm{N}=35$, and Afar $\mathrm{N}=23$ ) that are concentrated in the respective regional breeding center. Washera sheep breed is localized in west-east Gojam and AgewAwi zones of Amhara region (11 ${ }^{\circ} 00^{\prime} 0.00^{\prime \prime} \mathrm{N} 36^{\circ} 39^{\prime} 59.99^{\prime \prime}$ E). This breed is commonly known by its short fat tail, short-hair and large body size. They are reared for commercial mutton production. Menz sheep breeds are one of the most common sheep breeds in Ethiopia distributed in Menz, North Shewa zones of Amhara region ( $10^{\circ} 15^{\prime} 00.0^{\prime \prime}$ N39 $\left.30^{\circ} 00.0^{\prime \prime} \mathrm{E}\right)$. Their characteristic feature is a fatty short tail, well developed wooly undercoat with unique spiral horns. They are adapted to a cold environment and known for the production of meat and wool. Afar sheep named after Afar region. They are well adapted to harsh environments. They are a good source of fatty meat. Afar breeds from Amibara Woreda at a geographic coordinates 1033254, 0629012 were included in the study. Information on the phenotypes of the breeds was taken from Ethiopian Biodiversity booklet, 2018.

\section{DNA extraction and Polymerase Chain Reaction}

Genomic DNA was isolated from the EDTA treated blood using a commercial kit (Geneaid). PCR (Polymerase chain reaction) was carried out to amplify the coding region of the PRNP using forward (TCTGCAAGAAGCGACCAAAAC) and reverse (CACAGGAGGGGAAGAAAAGAGG) primers (NM_001009481.1). PCR mixture containing $200 \mu \mathrm{M}$ of each dNTP, $2 \mathrm{mmol} \mathrm{MgCl} 2,5 \mathrm{pmol}$ of each primer, 
0,05 U Taq polymerase, 10 X PCR buffer (Thermo Fisher Scientific Inc., USA), 10-50 ng of genomic DNA and $\mathrm{ddH} 2 \mathrm{O}$ to a final volume of 12,5 ul was used for PCR reaction. $2.5 \mathrm{ul}$ of PCR product was used for further analysis.

\section{Sequencing and bioinformatics}

After incubation with $1 \mathrm{U}$ Exo-SAP, a chain termination reaction was performed with BigDye ${ }^{\mathrm{TM}}$ terminator v3.1 Cycle Sequencing Kit (Thermo Fisher Scientific Inc., USA). At the final stage, all samples were purified by ethanol precipitation method and sequenced by Applied Biosystems 3500 genetic analyzer (Thermo Fisher Scientific Inc, USA). Chromatograms were checked with FinchTV and aligned using Mega v7.0 software. Hardy-Weinberg equilibrium state for the multilocus allele was calculated using Popgene 32.

\section{Results}

In the present study, novel variants were detected in the three native Ethiopian sheep PRNP protein-coding gene. Heterozygosity at nucleotide 296 and 297 resulted in two heterozygous amino acid substitution at position 99 i.e. H99Q (CAC->CAA) and H99L (CAC->CTA) Fig 1. Similarly, new substitutions at the already recognized polymorphic sites were identified i.e. A116T (GCA $\rightarrow$ ACA) and A116E (GCA $\rightarrow$ GAA). A synonymous substitution at the previously reported polymorphic site was also identified N103N (AAC-$>$ AAT). The variant N103N was not detected in Afar breed. The new variants are localized in the main functional domains of prion protein Fig 2. Additional polymorphisms at different positions i.e. G126A (heterozygous and homozygous), G127G, G127V (heterozygous), G127A (heterozygous), S138S, I142I (heterozygous), N146S (heterozygous and homozygous), R231R and L237L were identified. Most of those polymorphic sites were heterozygous for the specified loci Fig 3. Potential resistant variants M112T, M137T, R151C and N176K were not detected in the studied breeds.

In the current study, the highly susceptible haplotypes i.e. haplotypes categorized under groups 4 and 5 were not detected. Instead, ARQ was the dominant allele in all breeds. The haplotype ARR was observed only in Menz and Afar breeds with frequencies 0.02 and 0.05 respectively. ARQ/ARQ and ARH/ARH genotypes appeared in Menz breeds with 0.29 and 0.17 frequencies respectively while ARQ/ARQ genotype was dominant in Washera (0.68) and Afar (0.78) breeds. Neither the highly susceptible, VRQ, nor highly resistant, ARR, genotypes were observed in this study. In all of the samples analyzed; homozygous Leucine at position 141 was detected Table 1 . The population under study was not in Hardy-Weinberg proportion $\left(\chi_{6}^{2}: 35.2727 .58 p<0.05\right)$.

\section{Discussion}

In the current study, novel amino acid substitutions at a novel and previously identified polymorphic site were detected in the native Ethiopian sheep PRNP protein-coding gene. These substitutions $(\mathrm{H} 99 \mathrm{~L}$, N103N, A116T, and A116E) are spotted in a PK resistant region of the prion protein. Substitutions at amino acid 99 and 103 positions are localized more close to the signal peptide cleavage sites. Variants 
$A 116 T$ and $A 116 E$ are placed in hydrophobic palindrome region $\left(A_{116}\right.$ GAAAAG) which was described as the critical motif in the process of conversion of $\operatorname{PrP}^{\mathrm{C}}$ to $\mathrm{PrP}^{\mathrm{SC}}$ and its propagation [18]. Substitution with a different variant having different physicochemical properties might influence the conformational plasticity of prion protein and my further could tempt the emergence of new scrapie disease form.

Similar to previous studies, additional amino acid polymorphic sites i.e. G126A, G126A(heterozygous), G127G, G127V(heterozygous), G127A(heterozygous), S138S, I142IT, N146S, N146S(heterozygous), R231R, and L237L were identified [3-6]. In the present study, the variant at position 127 was in particular highly polymorphic. Amino acid variants at positions 126 and 127 are localized in the highly conserved Glycine repeat motif GAVVGGLGGYMLG which is reported to antagonize prion disease development by blocking amyloidal fibril formation [2]. Recent work on the Ethiopian goat PRNP protein-coding gene reported polymorphism at this position and implied its importance in the normal cellular function of prion protein [19].The synergetic effect of alterations in palindrome motif PrP (113-120) and Glycine repeat regions $\operatorname{PrP}(124-128)$ may strongly affect cellular prion protein conformational flexibility.

The possibility of infectious disease transmission from animal to animal, animal to human and viceversa makes genetic characterization of local breeds undeniably crucial especially in understanding and preventing transmittable disease [20]. So far, there is strong evidence that scrapie susceptibility and prolonged incubation period are linked to different PRNP genotypes. Known polymorphic alleles at position 136A/V, 154R/H, and 176R/H/Q are implicated in classical scrapie disease susceptibility [10]. Accordingly, the highest resistant genotype is ARR/ARR while VRQ/VRQ is the highest susceptible genotype. In atypical scrapie, AHQ, ARQ and ARR genotypes along with homozygosity for phenylalanine at position 141 are susceptible haplotypes. ARR genotype which is central protective haplotype in classical scrapie is not protective in atypical scrapie [11, 21].

In the current study, a significant proportion of the population's alleles under study were less resistant to classical and atypical scrapie (fall under scrapie resistance category groups 2 and 3 ). The haplotype, $A_{136} L_{141} R_{154} Q_{171}$, was predominant in the population under study. In the present study, the frequency of the ARQ allele was lower in Menz breed than the other two breeds. On the contrary, ARQ is the highest frequent allele in Afar breed. The relative allele frequency variation among breeds in this study might be directly related to the geographic barriers favoring inbreeding and later results in genetic distinction among breeds.

In countries such as Canada where scrapie was once apparently high, the resistant haplotype, ARR, became dominant over the previously reported VRQ and ARQ haplotype [7, 22]. Similarly, in India and China where scrapie case was never been epidemic, the predominant allele was ARQ [23,24]. Earlier works on sheep PRNP polymorphism from Israel, Iran, and Turkey revealed that ARQ was the dominant haplotype [25-29]. Atypical scrapie associated haplotype, ALRQ, was also prominent in the above listed countries where scrapie infection was not epidemic $[25,28]$. Studies from North African countries, Tunisia and Algeria reported ARQ, ARR, AHQ, ARH, and VRQ as major alleles. Those studies also identified identical polymorphisms which were reported in Spanish and Italian sheep and this similarity can be 
considered as a piece of evidence that some of Mediterranean surrounding countries' breeds had similar genetic background. If the transboundary infection had happened during the times when scrapie was epidemic in European countries, it is sound to expect a high frequent ARR and low frequent VRQ in Algeria and Tunisia $[30,31]$.

Earlier case-control studies linked specific alleles to survival rate after scrapie infection along with ARQ genotype. $T_{112} A R Q, A T_{137} R Q, A C_{151} R Q$, and $A R Q K_{176}$ haplotypes were identified as potential protective variants [11, 32, 33]. Accordingly, the detected homozygous Methionine at position 112\&137, Arginine at 151 , and Asparagine at 176 in all the analyzed samples potentiates the susceptibility of the breeds to scrapie.

Despite there have been cross-breeding practices especially community-based breeding programs in small ruminants in recent years $[15,16]$, in the present study frequency of homozygous genotypes were relatively dominant over heterozygous genotypes.

\section{Conclusion}

Two of the novel variations at position 99 and 103 that are placed closer to the cleavage site and variant at 116 which is spotted in the hydrophobic palindrome region along with variants at position 127 in Glycine repeat domain may influence the conformational flexibility of prion protein and /or introduce new form of scrapie disease. The predominant ARQ/ARQ genotype is a potential cue to assume that there was no natural selection against classical scrapie at least in the current study area. Considering the wild type variant $141 \mathrm{~L}$, Ethiopian native sheep breads are resistant to atypical scrapie. However, because of the identified disease susceptible genotypes and the spontaneity of atypical scrapie, the native Ethiopian sheep breeds are prone to contract scrapie. Therefore, these findings provide a valuable dataset that can be potentially integrated into selective breeding strategies against scrapie during inbreeding, crossbreeding and help to take precocious measures.

\section{Declaration}

Ethics approval and Consent to Participate-Animals were treated with great care and sample was taken according to the institute guideline. Ethical approval is deemed unnecessary according to the Ethiopian National Research Ethics Review Guideline/EFDRE ministry of science and Technology Sep $20145^{\text {th }}$ ed. Article 8.3.5.1, 10.2 and 10.5.1. Consent was granted to take blood samples from the respective regional state livestock development and promotion offices NS/AR/U-01/42/2010 and NS/AR/U01/41/2010.Genetic material export permit was assured from Ethiopian Biodiversity Institute, Ref. №.EBI71/943/2018.

Consent for publication-Not applicable

Availability of data and materials-The datasets used and/or analyzed during the current study are available from the corresponding author on reasonable request. 
Competing interest-The authors declare no conflict of interest.

Funding- No funding

Authors Contribution- ET involved in data collection, performed laboratory activities and wrote the manuscript. YY engaged in PCR and sequence optimization. CU formulated concept and organized the study. All authors have read and approved the manuscript.

Acknowledgment- The authors thank Mr. Abrham Assefa of EBI, Dr. Dinka Ayana of AAU College of Veterinary Medicine and Agriculture and Dr. Joram Mwasharo of ILRI, ICARDA for facilitating the work.

\section{Abbreviations}

PRNP gene: prion protein coding gene;PrPc: cellular prion; PrPSc. Scrapie form of prion; A: Alanine; C: Cysteine; D: Aspartic acid; E: Glutamate; G: Glycine; H: Histidine; I: Isoleucine; K: Lysine; L: Leucine, M: Methionine; N: Asparagine; P: Proline ; Q: Glutamine R: Arginine; S: Serine; T: Threonine; V: Valine; Y:Tyrosine.

\section{References}

1. Prusiner S. B. Prions. Proc Natl Acad Sci. 1998.95(23); 13363-13383.

2. Zhang J, and Zhang Y. Molecular dynamics studies on $3 \mathrm{D}$ structures of the hydrophobic region PrP(109-136). Acta Biochim Biophys Sin (Shanghai).2013. 45(6); 509-519.

3. Kdidi S, Yahyaoui H, Conte M, Chiappini B, Zaccaria G, Ben M,et al. PRNP polymorphisms in Tunisian sheep breeds. Livestock Science.2014. 167; 100-03.

4. Fantazi K, Sergio M, Samia K, Luca R, Hakim T, Rachid B, et al. Analysis of differences in prion protein gene (PRNP) polymorphisms between Algerian and Southern Italy's goats' Italian Journal of Animal Science.2018. 17; 578-85.

5. Vaccari G, Claudia A, Romolo N, Francesca R, Michela C, Michele A, et al.Prion Protein Alleles Showing a Protective Effect on the Susceptibility of Sheep to Scrapie and Bovine Spongiform Encephalopathy. Journal of Virology.2007. 81; 7306.

6. Yaman Y, Soysal M, Ün C. Evaluation of the genetic resistance status to classical and atypical scrapie in Karacabey merino rams. Turkish Journal of Veterinary and Animal Sciences.2015.39(6); 736 - 740.

7. Cameron C, Patricia B, Rebeccah M, Ana R, Hugh Y. Prion protein genotypes of sheep as determined from 3343 samples submitted from Ontario and other provinces of Canada from 2005 to 2012. Canadian journal of veterinary research = Revue canadienne de recherche veterinaire.2014. 78; 26066.

8. Laegreid W, Clawson L, Heaton P, Green T, Rourke I, Knowles P. Scrapie Resistance in ARQ Sheep. Journal of Virology.2008. 82; 10318. 
9. Tranulis Influence of the prion protein gene Prnp on scrapie susceptibility in sheep. Apmis.2002. 110; 33-43.

10. Baylis M, Goldmann W. The Genetics of Scrapie in Sheep and Goats. Current Molecular Medicine. 2004 385-96.

11. Thorgeirsdottir S, Sigurdarson, Thorisson H, Georgsson G, Palsdottir A (1999). PrP gene polymorphism and natural scrapie in Icelandic sheep. J Gen Virol .1999.80 (Pt 9); 2527-2534

12. Greenwood P.Federal disease control-scrapie. The Canadian veterinary journal = La revue veterinaire canadienne.2002. 43; 625-29.

13. Hagenaars J. Control of scrapie by selective breeding: what are we getting for free?. Veterinary Record.2014. 174; 528.

14. Truscott E, Ferguson M.Control of scrapie in the UK sheep population. Epidemiol Infect. 2009.137; 775-86.

15. Marshall K, Gibson J, Mwai O, Mwacharo J, Haile A, Getachew T, at al. Livestock Genomics for Developing Countries - African Examples in Practice. Frontiers in Genetics.2019.10;297

16. Getachew T, Haile A, Wurzinger M, Rischkowsky B, Gizaw S, Abebe A ,et al . Review of sheep crossbreeding based on exotic sires and among indigenous breeds in the tropics: An Ethiopian perspective. African Journal of Agricultural Research.2016. 11(11);901-911.

17. Teferedegn E, Tesfaye D, Ün C. Valuing the investigation of Prion diseases in Ethiopia. Int J Agric Sc Food Technol. 2019;doi: 17352/2455-815X.000034

18. Acevedo-Morantes $\mathrm{C}$, Wille $\mathrm{H}$. The structure of human prions: from biology to structural modelsconsiderations and pitfalls. Viruses2014; 6(10): 3875-3892

19. Vitale M, Migliore S, Tilahun B, Abdurahaman M, ToloneM, Sammarco I, et al.Two novel amino acid substitutions in highly conserved regions of prion protein (PrP) and a high frequency of a scrapie protective variant in native Ethiopian goats.BMC Vet Res 2019.15(1); 128.

20. Messenger M, Barnes N, Gray C. Reverse zoonotic disease transmission (zooanthroponosis): a systematic review of seldom-documented human biological threats to animals. PloS one. 2014. 9(2); e89055-e89055.

21. Lühken G, Anne B, Horst B, Martin E, Martin H, Georg E. Epidemiological and genetical differences between classical and atypical scrapie cases. Vet. Res.2007. 38; 65-80.

22. Harrington P, O'Rourke I, Feng Y, Rendulich J, Difruscio C, Balachandran A. Prion genotypes of scrapie-infected Canadian sheep 1998-2008. Can J Vet Res. 2010.74; 228-32.

23. Choudhary S, Gupta N,Jethra G. Genotyping of PRNP coding region for scrapie in Indian sheep. Iranian Journal of Veterinary Research.2014. 15(3); 293-296.

24. Guan F, Pan L, Li J, Tang H, Zhu C, Shi G. Polymorphisms of the prion protein gene and their effects on litter size and risk evaluation for scrapie in Chinese Hu sheep. Virus Genes. 2011.43(1); 147-152.

25. Alvarez L, Beatriz G, Metehan U, Fermin S, Juan J. Genetic variability in the prion rotein gene in five indigenous Turkish sheep breeds. Small Ruminant Research.2011. 99; 93-98. 
26. Frootan F, Nikbakht N, Ozgenturk O, Un C. Prion protein-coding gene (PRNP) variability in sheep from Turkey and Iran. Biochem Genet.2012. 50; 277-84.

27. Gootwine E,Abdulkhaliq K,. Jawasreh Z, Valle Zárate A.Screening for polymorphism at the prion protein (PrP) locus (PRNP) in Awassi and Assaf populations in Israel the Palestinian Authority and Jordan. Small Ruminant Research.2008. 77; 80-83.

28. Ün C, Oztabak K, Ozdemir N, Akıs I, Mengi A. Genotyping of PrP gene in native Turkish sheep breeds. Small Ruminant Research.2008. 74; 260-64.

29. Salami S, Reza Z, Mir O, Fatemeh R, Amir A. Allelic frequency and genotypes of prion protein at codon 136 and 171 in Iranian Ghezel sheep breeds. Prion.2011. 5; 228-31.

30. Djaout A, Chiappini B, Gaouar S, Afri-Bouzebda F, Conte M, Chekkal F et al. Biodiversity and selection for scrapie resistance in sheep: genetic polymorphism in eight breeds of Algeria. J Genet .2018.97(2); 453-461

31. Khorchani, Vaccari G .PRNP polymorphisms in Tunisian sheep breeds. Livestock Science.2014. 167, 100-103

32. Ikeda T, Horiuchi N, Ishiguro Y, Muramatsu G, Kai-Uwe, Shinagawa M (1995). Amino acid polymorphisms of PrP with reference to onset of scrapie in Suffolk and Corriedale sheep in Japan. J Gen Virol .1995.76; 2577-2581

33. Heaton P, Leymaster A, Freking A, Hawk A, Smith P, Keele W, et al. Prion gene sequence variation within diverse groups of U.S. sheep beef cattle and deer. Mamm Genome. 2003.14(11), 765-777.

\section{Tables}

Table 1 Scrapie associated allele and genotype frequencies of Menz, Washera Afar sheeps' $P R N P$ gene

\begin{tabular}{|c|c|c|c|c|}
\hline Overall Frequency & Menz & Washera & Afar & \\
\hline \multicolumn{5}{|l|}{ Allele } \\
\hline ARQ & 0.62 & 0.46 & 0.68 & 0.78 \\
\hline ARH & 0.29 & 0.41 & 0.26 & 0.17 \\
\hline AHQ & 0.07 & 0.11 & 0.06 & - \\
\hline ARR & 0.02 & 0.02 & - & 0.05 \\
\hline \multicolumn{5}{|l|}{ Genotype } \\
\hline ARQ/ARQ & 0.50 & 0.29 & 0.62 & 0.61 \\
\hline ARQ/ARH & 0.17 & 0.17 & 0.07 & 0.31 \\
\hline ARH/ARH & 0.20 & 0.31 & 0.20 & - \\
\hline ARQ/AHQ & 0.06 & 0.14 & 0.05 & - \\
\hline $\mathrm{ARH} / \mathrm{AHQ}$ & 0.02 & 0.03 & 0.03 & - \\
\hline $\mathrm{AHQ} / \mathrm{AHQ}$ & 0.02 & 0.03 & 0.03 & - \\
\hline ARQ/ARR & 0.02 & 0.03 & - & 0.04 \\
\hline ARH/ARR & 0.01 & - & - & 0.04 \\
\hline
\end{tabular}




\section{Figures}

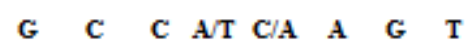

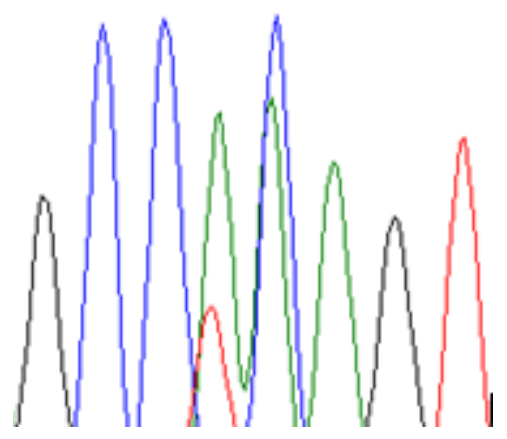

Figure 1

Heterozygosity at nucleotide 296 and 297 resulted in two heterozygous amino acid substitutions at position 99. Such Variants were seen in 3 animals from Afar, 2 from Washera and 1 from Menz. G127G

H99L

G127A

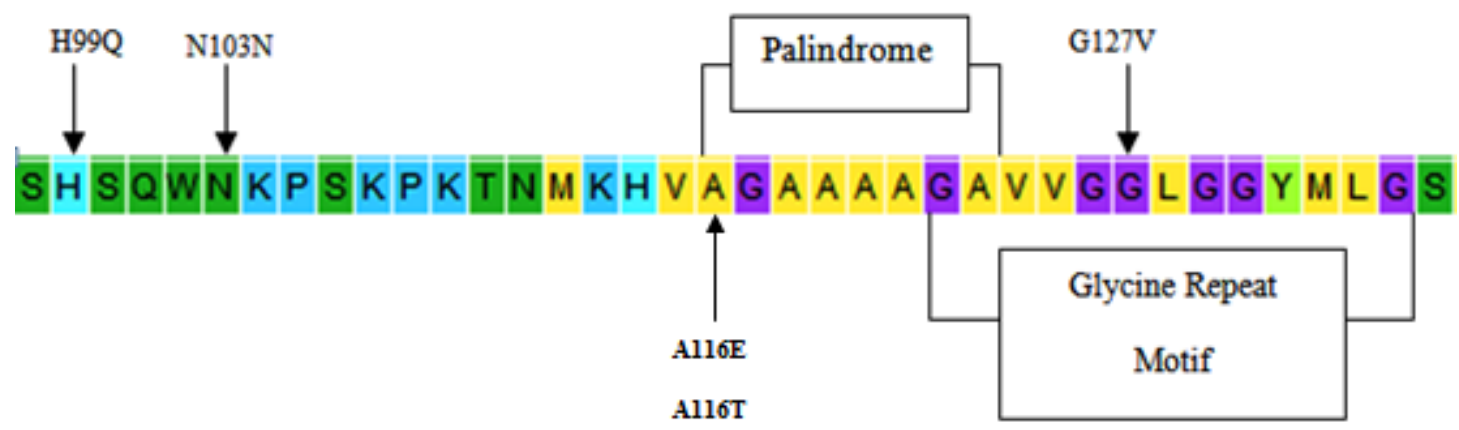

\section{Figure 2}

Polymorphisms at cleavage site, palindrome and highly conserved hydrophobic region of PrP. 


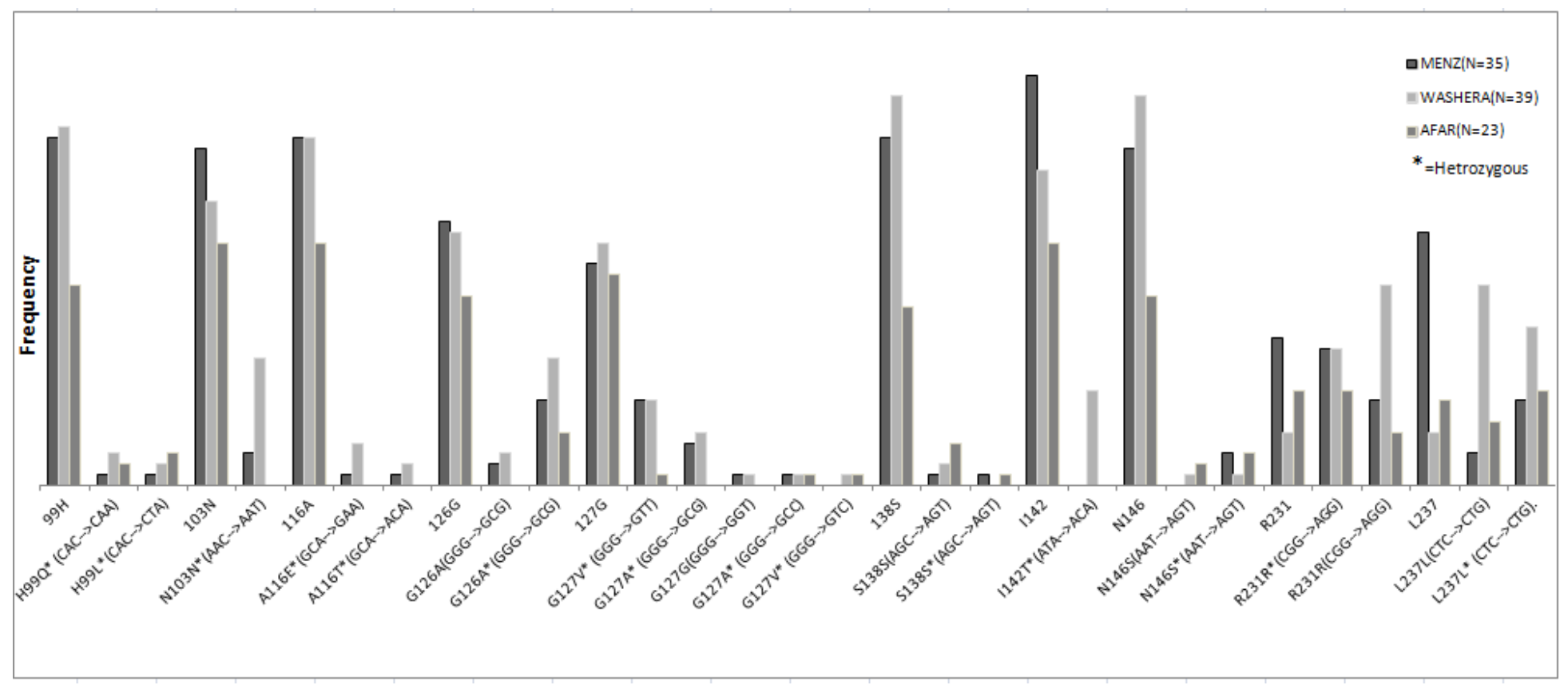

Figure 3

Amino acid substitutions over the length of the sequenced region. 